\title{
ARMAZENAMENTO SOB CONDIÇÕES AMBIENTE E ACEITABILIDADE DO MELÃO 'F1 JANGADA' PRODUZIDO EM SISTEMA HIDROPÔNICO
}

\author{
MARIA M. RINALDI ${ }^{1}$, DELVIO SANDRI ${ }^{2}$, DAYANNA M. C. NUNES ${ }^{3}$, \\ ADRIANA G. DO AMARAL ${ }^{3}$
}

\begin{abstract}
RESUMO: O objetivo deste trabalho foi determinar o período de armazenamento pós-colheita e a aceitabilidade pelo consumidor de melão híbrido 'F1 Jangada' (Cucumis melo L.), produzido em sistema hidropônico, mantido em condições ambiente $\left(22 \pm 2{ }^{\circ} \mathrm{C}\right.$ e umidade relativa de $\left.40 \pm 5 \%\right)$. O experimento compreendeu o período de 21-6-2005 a 2-8-2005. Foi utilizado o esquema fatorial $5 \times 2$, em delineamento experimental inteiramente casualizado, com cinco períodos de armazenamento $(0 ; 7 ; 21 ; 28$ e 42 dias) e dois tipos de substrato (areia e fibra de coco), com três repetições, em que cada repetição consistiu em cinco frutos de meloeiro. Foram avaliados o pH, a acidez titulável, os sólidos solúveis, a perda de massa fresca, a análise sensorial e a decisão de compra dos melões. Foram verificados efeitos do tipo de substrato e tempo de armazenamento sobre os valores de $\mathrm{pH}$ dos melões. A acidez titulável dos melões diminuiu significativamente nos primeiros sete dias de armazenamento, em ambos os substratos. Não foram verificados efeitos do tipo de substrato e tempo de armazenamento nos sólidos solúveis dos melões durante o armazenamento. Não houve diferença de perda de massa fresca dos frutos produzidos nos dois substratos, sendo de 7,1 $\pm 0,2 \%$, durante os 42 dias de armazenamento. $O$ tipo de substrato não interferiu na aparência geral, cor, textura e sabor dos melões. Aos 42 dias de armazenamento, os melões produzidos nos dois tipos de substrato apresentaram-se aceitáveis pelo consumidor. No entanto, os produzidos no substrato com areia apresentaram melhor aceitabilidade e decisão de compra ao longo do armazenamento.
\end{abstract}

PALAVRAS-CHAVE: Cucumis melo L., análise sensorial, vida útil pós-colheita.

\section{STORAGE UNDER ATMOSPHERE CONDITIONS AND ACCEPTABILITY OF THE MELON 'F1 JANGADA' CROPED IN HYDROPONIC SYSTEM}

\begin{abstract}
The objective of this work was to evaluate the storage period postharvest and acceptability by consumer of hybrid melon 'F1 Jangada' (Cucumis melo L.), produced in hydroponic system, stored in atmosphere conditions $\left(22 \pm 2{ }^{\circ} \mathrm{C}\right.$ and $40 \pm 5 \%$ relative humidity). The research was carried from June $21^{\text {st }}$ to August $2^{\text {nd }}, 2005$. It was applied a $5 \times 2$ factorial scheme in a completely randomized design, with five storage periods $(0 ; 7 ; 21 ; 28$ and 42 days) and two substrata types (sand and coconut fiber) with three replications, where each repetition consisted of five melon fruits. The $\mathrm{pH}$, titrable acidity, soluble solids, mass loss, sensorial analysis and purchase decision of the melons were analyzed. Effects of the substratum type and time of storage on the values of $\mathrm{pH}$ of the melons were verified. The titrable acidity of melon 'F1 Jangada' decreased significantly in the first seven days of storage in both substrata types. There were no effects of the substrata types and time of storage in the soluble solids of the melons during the storage. There was no difference of mass loss of the fruits produced in the two substrata, being of $7.1 \pm 0.2 \%$, during the 42 days of storage. The substratum type did not interfere in the general appearance, color, texture and flavor of the melons. On the $42^{\text {nd }}$ day of storage the melons produced in the two substrata types, were acceptable by the consumer. However, the croped melons in the substratum with sand presented better acceptability and purchase decision along the storage.
\end{abstract}

KEYWORDS: Cucumis melo L., sensorial analysis, postharvest shelflife.

\footnotetext{
${ }^{1}$ Eng ${ }^{\text {a }}$ Agrônoma, Docente de Ensino Superior IV, Faculdades de Engenharia Agrícola e Química Industrial, Universidade Estadual de Goiás - UEG, BR 153, km 98, Caixa Postal 459, Anápolis - GO, Fone: (OXX62) 3328-1160, rinaldi@ueg.br

${ }^{2}$ Eng $^{\circ}$ Agrícola, Docente de Ensino Superior IV, Faculdade de Engenharia Agrícola - UEG, sandri@ueg.br

${ }^{3}$ Alunas de graduação do curso de Engenharia Agrícola - UEG, daycalaca@ yahoo.com.br

Recebido pelo Conselho Editorial em: 16-2-2006
}

Aprovado pelo Conselho Editorial em: 13-9-2006 


\section{INTRODUÇÃO}

O interesse pelo cultivo do melão tem aumentado nos últimos anos, tanto para exportação como para o mercado interno; no entanto, a adoção de tecnologias que visem ao controle de qualidade e à conservação pós-colheita, não tem acompanhado o ritmo da produção, resultando, na maioria das vezes, em elevadas perdas. No Estado de Goiás, praticamente todo o melão consumido é importado de outras regiões, fazendo com que o produto tenha custo mais elevado e qualidade inferior, uma vez que nem sempre o sistema de transporte e o armazenamento adotado são os mais adequados. As variedades de meloeiro preferencialmente cultivadas no Brasil são do grupo Inodorus, representadas pelo melão 'Amarelo', produzidas em maior escala, e que apresentam excelente conservação até 35 dias em temperatura ambiente (COCOZZA, 1997).

No Brasil, a maior parte da produção do melão é realizada em condições de campo; no entanto, segundo ALMEIDA (2002), o cultivo em casa de vegetação tornou-se importante opção para o agricultor, onde é possível a obtenção de altas produtividades e melhor qualidade dos frutos. Apesar de ser considerado um produto de elevado valor comercial e ser apreciado por suas características sensoriais, o melão apresenta vida útil pós-colheita relativamente curta à temperatura ambiente, o que tem dificultado, consideravelmente, a sua comercialização nos mercados mais distantes dos centros de produção, contribuindo para o elevado índice de perdas pós-colheita desse fruto.

OLIVEIRA (1992) verificou vida útil pós-colheita inferior a cinco dias para o melão Arava (tipo Galia), armazenado à temperatura de $30^{\circ} \mathrm{C}$ e umidade relativa de $61 \%$. MORAIS et al. (2004) estudaram quatro genótipos de melão tipo Gália, e o genótipo Solarking apresentou melhor potencial de vida útil pós-colheita. A aparência interna limitou o tempo de vida útil pós-colheita do genótipo Total em apenas seis dias. MENDONÇA et al. (2004) estudaram o armazenamento de melão-amarelo, híbrido RX 20094, sob temperatura ambiente atingindo vida útil de 25 dias a $30{ }^{\circ} \mathrm{C}$. ALVES (2000) avaliou a vida útil dos frutos de melão híbridos Gold Mine e Duna, sob condições ambiente (temperatura de $26^{\circ} \mathrm{C} \pm 2{ }^{\circ} \mathrm{C}$; umidade relativa de $65^{\circ} \mathrm{C} \pm 2 \%$ ), os quais foram colhidos no estádio de maturação comercial e conservaram-se por 35 e 28 dias, respectivamente. A partir desse período, apresentaram sintomas de senescência, como colapso interno, sementes soltas e manchas vermelho-bronzeadas na superfície.

MENDONÇA et al. (2005) estudaram a vida útil pós-colheita de melões Orange Flesh tipo

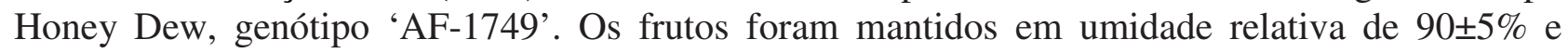
temperaturas de $5{ }^{\circ} \mathrm{C}, 7^{\circ} \mathrm{C}$ e ambiente. Foi observada perda de peso e de firmeza da polpa mais acentuadas à temperatura ambiente. Os frutos armazenados às temperaturas de $5{ }^{\circ} \mathrm{C}$ e $7{ }^{\circ} \mathrm{C}$ mantiveram qualidade comercial até aos 28 dias. Não houve nenhum efeito da temperatura sob o conteúdo de sólidos solúveis. Quanto à vida útil e qualidade pós-colheita de melões produzidos em sistema hidropônico, na literatura especializada, não foram encontrados dados que contemplem essas informações.

Após a colheita, o processo respiratório em frutos e hortaliças não é tão eficiente, uma vez que não é suprido pelo processo fotossintético. Entretanto, quanto mais rápido o produto respira e amadurece, maior é a quantidade de calor gerado e menor a vida pós-colheita (CHITARRA, 1998). Assim, alguns fatores que melhoram a qualidade e a vida útil desses produtos são: colheita no ponto ótimo de maturação, minimização de danos mecânicos, umidade relativa alta e condições adequadas de temperatura, que, quando altas, contribuem para aumentar a atividade microbiana e as alterações químicas e enzimáticas (FONSECA et al., 2002; CASTILLO, 2003; VANETTI, 2004).

Os frutos sofrem grandes transformações físicas e químicas durante a maturação, representando extenso espectro de processos degradativos, simultâneos ou seqüenciais, conduzindo ao aprimoramento dos atributos de qualidade, notadamente de pigmentação, da textura, da cor, do sabor e do aroma. Os mesmos possuem diferentes ácidos orgânicos livres ou em forma de 
nutrientes que degradam rapidamente depois da colheita se o fruto for mantido à temperatura ambiente (CHITARRA, 1998; CORTEZ et al., 2002).

A transpiração é uma das principais causas da perda de massa fresca, tendo importante papel na qualidade comercial dos produtos hortícolas, podendo ser devida a alterações de origem biológica ou à liberação de dióxido de carbono pelas trocas gasosas (GAC (1970), citado por CARMO (2004) e MAGUIRE et al. (2001)). O aumento da respiração causa reações químicas e bioquímicas responsáveis pelas modificações da qualidade sensorial e nutricional, reduzindo o teor vitamínico (JACOMINO et al., 2004). A perda de água aumenta o murchamento e reduz a consistência, afetando a aparência ideal para o consumo de muitos frutos (AWAD, 1993; VICENTINI et al., 1999). A manutenção da temperatura baixa e da umidade relativa do ar alta (> 90\%) são os meios mais eficazes de reduzir a perda de água, porém umidade relativa alta pode favorecer o desenvolvimento de microrganismos (ALVES, 2000).

O conhecimento da vida útil pós-colheita de um produto é importante para determinar o tipo de armazenamento, o transporte e o mercado que poderá atingir. A vida útil está diretamente relacionada com a qualidade microbiológica, que, segundo VANETTI (2004), irá contribuir com as alterações das características sensoriais do produto, tais como: cor, aroma, textura e aparência. A cor é o atributo de qualidade mais atrativo para o consumidor. O sabor é afetado pelo odor e pela textura, o que faz com que seja um atributo de qualidade complexo, difícil de medir objetivamente (CHITARRA, 1998). A textura é um dos atributos de qualidade de maior importância em frutas e hortaliças, que, junto com o aroma, o sabor e a aparência geral, pode ser motivo de descarte do produto (GUERRERO, 1993).

Diante do exposto, este trabalho foi realizado com o objetivo de determinar o período de armazenamento pós-colheita e a aceitabilidade pelo consumidor do melão híbrido cv F1 Jangada, produzido em sistema hidropônico, utilizando como substrato areia e fibra de coco, e mantido sob condições ambiente.

\section{MATERIAL E MÉTODOS}

O melão foi produzido em empresa particular, localizada na Fazenda Formiga, município de

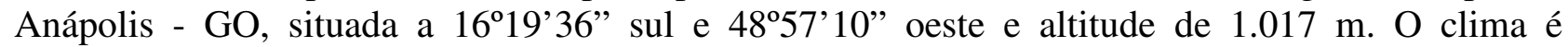
considerado mesotérmico e úmido, classificado como provável clima tropical de altitude, temperatura média anual de $22{ }^{\circ} \mathrm{C}$. Ocorrem baixas temperaturas em junho e julho, com média mínima de $10^{\circ} \mathrm{C}$.

O cultivo do meloeiro foi realizado em casa de vegetação em formato de túnel alto, com 7,0 m de largura e 50,0 m de comprimento. Possuía fechamento lateral e frontal com tela tipo clarite de polietileno transparente $(50 \%)$ até a altura do pé-direito, que é de 3,0 m. A cobertura é de polietileno de baixa densidade transparente, com $150 \mu \mathrm{m}$ de espessura, contendo difusor de luz e antivírus, aditivado com antiultravioleta (UV).

O híbrido de meloeiro (Cucumis melo L.) produzido foi o F1 Jangada. A semeadura foi realizada em bandejas de poliestireno, com 128 células, contendo fibra de coco, sendo o transplantio realizado 21 dias após a semeadura (8-4-2005).

Foram construídos seis leitos de cultivo com 0,2 $\mathrm{m}$ de largura e 0,25 $\mathrm{m}$ de profundidade, impermeabilizados com plástico, preenchidos com substratos e cobertos com "mulching", apresentando pequena inclinação $(0,5 \%)$ para drenar o excedente de solução nutritiva aplicada.

Foram utilizados como substratos areia lavada, apresentando módulo de finura médio de 2,21 mm e dimensão máxima característica de $6,3 \mathrm{~mm}$, e fibra de coco em pó (Padrão 11 (100\% fibra) - Anafibra), com valores iniciais de condutividade elétrica de 0,1 e 0,4 dS m $\mathrm{m}^{-1}$, respectivamente.

A solução nutritiva foi preparada utilizando-se das mesmas concentrações de uma formulação específica para meloeiro, sugerida por CASTELLANE \& ARAUJO (1995), sendo 
adicionadas as seguintes quantidades em g $1.000 \mathrm{~L}^{-1}$ de água: nitrato de cálcio (900), nitrato de potássio (455), sulfato de potássio (22), fosfato de potássio $\left(170,35 \%\right.$ de $\mathrm{K}_{2} \mathrm{O}$ e $53 \%$ de $\mathrm{P}_{2} \mathrm{O}_{5}$ ), sulfato de magnésio (246) ferrilênio (37), sulfato de manganês $(2,54)$, bórax $(1,15)$, sulfato de zinco $(1,15)$, sulfato de cobre $(0,12)$ e molibdato de sódio $(0,12)$.

A aplicação da solução nutritiva foi realizada uma vez, no período da manhã, e outra na parte da tarde, por cerca de 10 minutos, utilizando-se de linhas de gotejadores com 48,0 m de comprimento, instaladas a $0,05 \mathrm{~m}$ da linha de plantas, com pressão de $98 \mathrm{kPa}$. O controle da concentração da solução foi realizado por medidas diárias da condutividade elétrica da solução nutritiva, apresentando valores médios de $2,5 \mathrm{dS} \mathrm{m}^{-1}$.

A colheita foi realizada de forma manual, aos 72 dias após o transplantio, cortando-se o pedúnculo para que não houvesse lesões por atrito. O critério utilizado para determinar o ponto de colheita dos frutos de meloeiro foi a coloração da casca, que deveria estar bem amarela, e os sólidos solúveis em torno de $9{ }^{\circ}$ Brix. Após a colheita, os frutos foram submetidos à seleção manual, descartando-se os frutos portadores de imperfeições facilmente detectáveis e desuniformidade de maturação. Em seguida, foram transportados em sacos plásticos sem refrigeração para o laboratório de Tecnologia de Fermentações e Enzimologia da Unidade Universitária de Ciências Exatas e Tecnológicas - UnUCET, da Universidade Estadual de Goiás UEG, onde foram mantidos em temperatura ambiente $\left(22 \pm 2{ }^{\circ} \mathrm{C}\right.$ e umidade relativa do ar de $40 \pm$ $5 \%$ ) até o final do experimento.

Foram avaliados o pH, a acidez titulável, os sólidos solúveis, a perda de massa fresca, a vida útil a partir de análise sensorial de aceitabilidade (considerando a aparência geral, cor, textura e sabor) e a decisão de compra, na colheita e após 7; 21; 28 e 42 dias de armazenamento.

$\mathrm{O}$ delineamento experimental utilizado foi o inteiramente casualizado, em esquema fatorial 5 x 2 (cinco períodos de armazenamento e dois tipos de substrato - areia e fibra de coco), com três repetições, no qual cada repetição consistiu em cinco frutos de meloeiro. Os dados obtidos foram submetidos à análise de variância, com posterior comparação de médias pelo teste de Tukey, a 5\% de probabilidade, utilizando-se do Software ESTAT - Unesp, Câmpus de Jaboticabal - SP.

Para a determinação do $\mathrm{pH}$, foram coletadas, aleatoriamente, cinco amostras de cada tratamento, retirando-se a casca e as sementes do melão, sendo triturados em liquidificador doméstico, realizando-se as leituras com peagômetro, utilizando-se do potenciômetro digital Tecnal - TE C3- MP.

Para a análise da acidez titulável, titularam-se 10 gramas de polpa homogeneizada e filtrada, diluída em $90 \mathrm{~mL}$ de água destilada, com solução padronizada de hidróxido de sódio $(\mathrm{NaOH})$ a $0,1 \mathrm{~N}$. Utilizou-se como ponto de viragem, o $\mathrm{pH} 8,1$, sendo o resultado expresso em g de ácido cítrico anidro $100 \mathrm{~g}^{-1}$ de polpa.

Para a determinação dos sólidos solúveis, foram colocadas algumas gotas de polpa homogeneizada e filtrada de cada amostra na placa do refratômetro com compensação automática de temperatura, com precisão de $0,1 \%$. Os resultados foram expressos em ${ }^{\circ}$ Brix.

A determinação da perda de massa fresca (PMF) foi realizada utilizando-se de balança digital, com precisão de $0,01 \mathrm{~g}$, e capacidade para $10 \mathrm{~kg}$. Os resultados foram expressos em percentagem, de acordo com a eq. (1):

$$
P M F=\frac{\text { Peso Inicial }- \text { Peso Final }}{\text { Peso Inicial }} 100
$$

Para a análise sensorial, foi utilizada a metodologia classificada como Método Afetivo Quantitativo, em que 30 julgadores não-treinados, consumidores de melão, avaliaram os seguintes atributos de qualidade do produto: aparência geral, cor, textura e sabor. Para a avaliação desses atributos, foi realizado teste de aceitabilidade, utilizando-se de escala hedônica de cinco pontos, enumeradas em ordem decrescente de 5 a 1 : sendo $5=$ gostei muito; $4=$ gostei; $3=$ não gostei $/$ nem 
desgostei; 2 = desgostei, e 1 = desgostei muito. Os julgadores indicaram o grau que lhes agradou cada amostra, escolhendo a categoria apropriada. Para as análises, as amostras foram fornecidas aos julgadores de forma aleatória, colocadas em pratos de vidro, codificadas como amostra "A" e amostra "B", sendo fornecida para cada amostra uma ficha de avaliação sensorial para cada um dos 30 julgadores. Foi estabelecido previamente que valores menores que três seriam considerados inadequados para a aceitabilidade do produto, ou seja, de comercialização. Dessa forma, a vida útil dos melões submetidos aos tratamentos seguiu um mínimo de aceitabilidade para os atributos estudados, sendo rejeitado quando a nota obtida foi menor que três, sendo considerado indesejável para o consumo e eliminado das análises.

Os julgadores também opinaram sobre a decisão de compra, considerando as seguintes alternativas: certamente compraria, provavelmente compraria, talvez compraria/talvez não compraria, provavelmente não compraria e certamente não compraria.

\section{RESULTADOS E DISCUSSÃO}

Melões 'F1 Jangada' produzidos em substrato de areia apresentaram diferença significativa aos 28 dias de armazenamento em relação aos 42 dias, nos quais o $\mathrm{pH}$ foi significativamente maior. No substrato fibra de coco, os melões com 28 dias de armazenamento apresentaram pH significativamente inferior ao dia zero e 21 dias de armazenamento (Tabela 1). Foi verificada diferença significativa no $\mathrm{pH}$ dos melões produzidos nos diferentes substratos aos 42 dias de armazenamento, quando os melões produzidos no substrato areia apresentaram maior valor de $\mathrm{pH}$. Durante os 42 dias de armazenamento, os valores de $\mathrm{pH}$ dos melões produzidos no substrato areia estiveram entre 5,7 e 6,1. No substrato fibra de coco, os valores de $\mathrm{pH}$ dos melões foram entre 5,6 e 6,1. LIMA et al. (2004) observaram, para o melão Galia 'Solar King', variação expressiva de pH só até o quarto dia após a colheita, com redução de 6,6 para 6,2.

TABELA 1. Valores médios de $\mathrm{pH}$, acidez titulável, sólidos solúveis ( ${ }^{\circ}$ Brix) e perda de massa fresca de melões 'F1 Jangada', em função do tipo de substrato utilizado na produção hidropônica (areia e fibra de coco) e armazenamento em condições ambiente ( $22 \pm$ $2{ }^{\circ} \mathrm{C}$ ) e umidade relativa do ar de $40 \pm 5 \%$.

\begin{tabular}{|c|c|c|c|c|c|c|c|c|}
\hline \multirow{2}{*}{$\begin{array}{l}\text { Armazenamento } \\
\text { (dias) }\end{array}$} & \multicolumn{2}{|c|}{$\mathrm{pH}$} & \multicolumn{2}{|c|}{$\begin{array}{l}\text { Acidez Titulável (g de } \\
\text { ácido cítrico anidro } \\
100 \mathrm{~g}^{-1} \mathrm{de} \text { polpa) }\end{array}$} & \multicolumn{2}{|c|}{$\begin{array}{l}\text { Sólidos Solúveis } \\
\qquad\left({ }^{\circ} \text { Brix }\right)\end{array}$} & \multicolumn{2}{|c|}{$\begin{array}{l}\text { Perda de Massa } \\
\text { Fresca }(\%)^{*}\end{array}$} \\
\hline & Areia & $\begin{array}{c}\text { Fibra de } \\
\text { coco }\end{array}$ & Areia & $\begin{array}{c}\text { Fibra de } \\
\text { coco }\end{array}$ & Areia & $\begin{array}{l}\text { Fibra de } \\
\text { coco }\end{array}$ & Areia & $\begin{array}{c}\text { Fibra de } \\
\text { coco }\end{array}$ \\
\hline 0 & 5,9 Aab & $6,1 \mathrm{Aa}$ & $1,08 \mathrm{Aa}$ & $0,91 \mathrm{Aa}$ & $8,27 \mathrm{Aa}$ & $8,43 \mathrm{Aa}$ & $0,0 \mathrm{a}$ & $0,0 \mathrm{a}$ \\
\hline 7 & 5,9 Aab & 5,9 Aab & $0,10 \mathrm{Ab}$ & $0,10 \mathrm{Ab}$ & 7,60 Aa & 6,90 Aa & $2,2 \mathrm{a}$ & $1,9 \mathrm{a}$ \\
\hline 21 & 5,9 Aab & 6,0 Aa & $0,13 \mathrm{Ab}$ & $0,11 \mathrm{Ab}$ & 7,90 Aa & $8,80 \mathrm{Aa}$ & $4,5 \mathrm{a}$ & $4,1 \mathrm{a}$ \\
\hline 28 & $5,7 \mathrm{Ab}$ & $5,6 \mathrm{Ab}$ & $0,11 \mathrm{Ab}$ & $0,11 \mathrm{Ab}$ & $8,00 \mathrm{Aa}$ & $8,00 \mathrm{Aa}$ & $5,3 \mathrm{a}$ & $5,0 \mathrm{a}$ \\
\hline 42 & $6,1 \mathrm{Aa}$ & $5,7 \mathrm{Bab}$ & $0,11 \mathrm{Ab}$ & $0,10 \mathrm{Ab}$ & $9,10 \mathrm{Aa}$ & $7,83 \mathrm{Aa}$ & $7,3 \mathrm{a}$ & $7,1 \mathrm{a}$ \\
\hline Média geral & \multicolumn{2}{|c|}{5,9} & \multicolumn{2}{|c|}{0,254} & \multicolumn{2}{|c|}{8,08} & \multicolumn{2}{|c|}{ - } \\
\hline Desvio-Padrão & \multirow{2}{*}{\multicolumn{2}{|c|}{0,154}} & \multicolumn{2}{|c|}{0,132} & \multicolumn{2}{|c|}{1,025} & \multicolumn{2}{|c|}{. } \\
\hline C.V. (\%) & & & \multicolumn{2}{|c|}{52,08} & \multicolumn{2}{|c|}{12,68} & \multicolumn{2}{|c|}{-} \\
\hline
\end{tabular}

Médias seguidas por letras iguais não diferem entre si, a 5\%, pelo teste de Tukey.

A $1^{\underline{a}}$ letra compara os diferentes tipos de substrato dentro do mesmo tempo de armazenamento.

A $2^{\underline{a}}$ letra compara o mesmo tipo de substrato dentro dos diferentes tempos de armazenamento.

*Comparação de médias somente entre substratos.

A acidez titulável dos frutos apresentou variação significativa entre o dia da colheita e os demais períodos de armazenamento. A acidez titulável é um dos fatores fundamentais que afetam o sabor. Nos melões, o ácido mais abundante é o cítrico, sendo degradado rapidamente, como verificado principalmente até aos 7 dias de armazenamento. 
Não ocorreu variação significativa dos sólidos solúveis dos frutos de meloeiro produzidos nos dois tipos de substrato e dias de armazenamento. O melão híbrido 'F1 Jangada' apresentou valores médios de sólidos solúveis entre $6,9^{\circ}$ e $8,8^{\circ}$ Brix, no substrato de fibra de coco, e $7,6^{\circ}$ e $9,1{ }^{\circ}$ Brix, para a areia (Tabela 1), inferiores aos considerados adequados para o mercado exportador, que deve ser em torno de $10{ }^{\circ}$ Brix. De acordo com CUNHA (1994), o valor médio dos sólidos solúveis ( ${ }^{\circ}$ Brix) em melões está entre $9^{\circ}$ e $10{ }^{\circ}$ Brix para os híbridos AF 646, Gold Star, AF 682 e TSX 32096, e entre $8^{\circ}$ e $9{ }^{\circ}$ Brix para o Gold Pride, Gold Mine, Yellow Queen, RML, PX 4910606, Rochedo, AF 2409 e SUNEX. Esses dados são referentes à média de apenas quatro locais: Mossoró, Alto dos Rodrigues e Baraúna, no Rio Grande do Norte, e Quixeré, no Ceará. MICCOLIS \& SALTVEIT (1995) também não observaram variação significativa nos valores de sólidos solúveis, quando compararam cultivares de melão do grupo Inodorus Amarelo, Golden Beauty Casaba, Honeydew, Honey Loupe, Juan Canary e Paceco, após o armazenamento a $7{ }^{\circ} \mathrm{C}$, $12{ }^{\circ} \mathrm{C}$ e $15{ }^{\circ} \mathrm{C}$, por três semanas, seguidas por três dias a $20{ }^{\circ} \mathrm{C}$. O mesmo ocorreu com FARIA et al. (2003), observando que o teor de sólidos solúveis dos frutos do melão híbrido AF 682 aumentou com a aplicação de nitrogênio produzido no Latossolo, e os micronutrientes não exerceram efeito significativo consistente, observando valores sempre maiores que $10^{\circ} \mathrm{Brix}$.

LIMA et al. (2004) observaram, para o melão Galia, que os sólidos solúveis variaram em conseqüência do tempo de armazenamento, diminuindo de 12,9 para 9,7 ${ }^{\circ}$ Brix. Segundo MIR \& BEAUDRY (2002) e VALERO \& RUIZ (1998), a redução dos sólidos solúveis é normal, sendo justificada pelo elevado consumo desse substrato para suprir a energia necessária às reações metabólicas, pois os açúcares constituem importante substrato respiratório. Valores maiores de sólidos solúveis observados em alguns períodos do armazenamento, apesar de não serem significativos, podem ter ocorrido devido à variabilidade das amostras ou à perda de água ocorrida durante o armazenamento.

Não houve diferença significativa de perda de massa fresca entre os frutos submetidos aos diferentes tratamentos. A perda de massa fresca aos 42 dias de armazenamento foi de 7,3\% e 7,1\% para os frutos produzidos no substrato de areia e fibra de coco, respectivamente (Tabela 1). LIMA et al. (2004) verificaram que, em melões Galia 'Solar King', tratados com 1-metilciclopropeno, 20 dias após a colheita, o valor médio de perda de massa foi igual a 4,34\%, não observando murcha dos frutos. A perda de água está associada à perda de massa e à diminuição da qualidade dos frutos, principalmente por alterações na textura. Durante o armazenamento, a perda de massa do melão pode representar sério prejuízo econômico, pois, normalmente, o fruto é vendido por unidade de massa (PERONI, 2002).

A perda de massa fresca não causou enrugamento da casca do melão híbrido 'F1 Jangada' suficiente para afetar, significativamente, a aparência externa, sendo corroborados pelos resultados obtidos por MORAIS et al. (2004), ao estudarem o potencial de vida útil em quatro genótipos de melão tipo Gália.

Não houve diferença significativa entre os tratamentos em nenhuma das datas de análise sensorial para os atributos aparência geral, cor, textura e sabor (Tabela 2). No entanto, aos 42 dias de armazenamento, os melões produzidos em sistema hidropônico com substrato de areia apresentaram aparência geral, cor, textura e sabor levemente superiores ao substrato fibra de coco, não sendo significativo. Em nenhum dos tratamentos e atributos avaliados houve nota menor que três, parâmetro utilizado para classificar a não-aceitabilidade, o que justificaria a continuação das análises por maior período, uma vez que ainda apresentava qualidade comercial aceitável.

Observou-se, ainda, que a cor para os frutos do tratamento com substrato de areia apresentou menor oscilação ao longo do período de armazenamento, ao contrário do produzido com o substrato fibra de coco, que mostrou nota média mais elevada aos sete dias de armazenamento e redução aos 28 dias de armazenamento.

No atributo textura, o tratamento com melões produzidos em fibra de coco, até os 28 dias de armazenamento, manteve alta aceitação, decaindo a partir dessa data. Observa-se que o dia zero de 
armazenamento, em relação ao sétimo dia de armazenamento, apresentou crescimento da aceitabilidade, possivelmente devido ao momento em que o fruto foi colhido, não estando no amadurecimento comercial, conforme demonstrado pelos valores de sólidos solúveis.

TABELA 2. Valores médios de aparência geral, cor, textura e sabor de melões 'F1 Jangada', em função do tipo de substrato utilizado na produção hidropônica (areia e fibra de coco) e armazenamento em condições ambiente $\left(22 \pm 2{ }^{\circ} \mathrm{C}\right.$ e umidade relativa do ar de $40 \pm$ $5 \%)$

\begin{tabular}{|c|c|c|c|c|c|c|c|c|c|c|}
\hline \multirow{3}{*}{$\begin{array}{l}\text { Análise } \\
\text { Sensorial }\end{array}$} & \multicolumn{10}{|c|}{ Tempo de Armazenamento (dias) } \\
\hline & \multicolumn{2}{|c|}{0} & \multicolumn{2}{|r|}{7} & \multicolumn{2}{|c|}{21} & \multicolumn{2}{|c|}{28} & \multicolumn{2}{|c|}{42} \\
\hline & Areia & $\begin{array}{c}\text { Fibra } \\
\text { de coco }\end{array}$ & Areia & $\begin{array}{c}\text { Fibra } \\
\text { de coco }\end{array}$ & Areia & $\begin{array}{c}\text { Fibra } \\
\text { de coco }\end{array}$ & Areia & $\begin{array}{c}\text { Fibra } \\
\text { de coco }\end{array}$ & Areia & $\begin{array}{c}\text { Fibra } \\
\text { de coco }\end{array}$ \\
\hline Aparência geral & $4,4 \mathrm{a}$ & $4,0 \mathrm{a}$ & $4,4 \mathrm{a}$ & $4,5 \mathrm{a}$ & $4,2 \mathrm{a}$ & $4,5 \mathrm{a}$ & $4,3 \mathrm{a}$ & $4,5 \mathrm{a}$ & $4,4 \mathrm{a}$ & $3,8 \mathrm{a}$ \\
\hline Cor & $4,4 \mathrm{a}$ & $4,0 \mathrm{a}$ & $4,2 \mathrm{a}$ & $5,0 \mathrm{a}$ & $4,1 \mathrm{a}$ & $4,0 \mathrm{a}$ & $4,3 \mathrm{a}$ & $3,5 \mathrm{a}$ & $4,3 \mathrm{a}$ & $4,0 \mathrm{a}$ \\
\hline Textura & $3,9 \mathrm{a}$ & $4,5 \mathrm{a}$ & $4,5 \mathrm{a}$ & $5,0 \mathrm{a}$ & $4,1 \mathrm{a}$ & $4,0 \mathrm{a}$ & $4,5 \mathrm{a}$ & $4,0 \mathrm{a}$ & $4,3 \mathrm{a}$ & $3,7 \mathrm{a}$ \\
\hline Sabor & $4,2 \mathrm{a}$ & $4,0 \mathrm{a}$ & $4,4 \mathrm{a}$ & $4,5 \mathrm{a}$ & $4,0 \mathrm{a}$ & $4,5 \mathrm{a}$ & $4,3 \mathrm{a}$ & $3,0 \mathrm{a}$ & $4,6 \mathrm{a}$ & $3,3 \mathrm{a}$ \\
\hline
\end{tabular}

Médias seguidas de mesma letra não diferem, a 5\% de probabilidade, para o teste de Tukey, entre os substratos areia e fibra de coco para cada atributo analisado e datas de amostragem.

O melão produzido com fibra de coco mostrou ser menos saboroso a partir dos 21 dias do armazenamento, contribuindo para a redução de sua vida útil. Os produzidos no tratamento com areia obtiveram maior aceitabilidade, principalmente de 21 aos 42 dias de armazenamento, caracterizando maior vida útil. Esse comportamento é interessante ao produtor, uma vez que o custo para implantar a cultura do melão, utilizando areia como substrato, é bem menor que o uso de fibra de coco.

A cada dia de análise sensorial, os provadores opinaram sobre a decisão de compra, sendo esses resultados apresentados na Tabela 3.

TABELA 3. Decisão de compra de melões 'F1 Jangada', em função do tipo de substrato utilizado na produção hidropônica (areia e fibra de coco) e armazenamento em condições ambiente $\left(22 \pm 2{ }^{\circ} \mathrm{C}\right.$ e umidade relativa do ar de $\left.40 \pm 5 \%\right)$.

\begin{tabular}{|c|c|c|c|c|c|c|c|c|c|c|}
\hline \multirow{3}{*}{ Decisão de Compra } & \multicolumn{5}{|c|}{ Areia } & \multicolumn{5}{|c|}{ Fibra de coco } \\
\hline & \multicolumn{5}{|c|}{ Dias de Armazenamento } & \multicolumn{5}{|c|}{ Dias de Armazenamento } \\
\hline & 0 & 7 & 21 & 28 & 42 & 0 & 7 & 21 & 28 & 42 \\
\hline Certamente compraria & 11 & 14 & 10 & 11 & 15 & 10 & 13 & 13 & 8 & 6 \\
\hline Provavelmente compraria & 12 & 12 & 6 & 14 & 9 & 11 & 9 & 7 & 9 & 6 \\
\hline Talvez compraria/talvez não compraria & 4 & 1 & 8 & 1 & 6 & 5 & 6 & 7 & 9 & 7 \\
\hline Provavelmente não compraria & 3 & 3 & 6 & 4 & 0 & 2 & 1 & 3 & 4 & 6 \\
\hline Certamente não compraria & 0 & 0 & 0 & 0 & 0 & 2 & 1 & 0 & 0 & 5 \\
\hline
\end{tabular}

No primeiro dia da análise sensorial, os melões submetidos ao tratamento com areia obtiveram melhor decisão de compra, tendo em vista que 12 provadores, provavelmente comprariam, e 11 provadores, certamente comprariam. A menor aceitabilidade do melão produzido com substrato de fibra de coco pode ser pelo fato de o ponto de colheita não ter sido o mais adequado, podendo ter influenciado na cor e no sabor. Observa-se que dois provadores decidiram que certamente não comprariam o melão produzido com substrato fibra de coco, enquanto nenhum provador teve essa opinião para os do substrato areia.

Para o sétimo dia de armazenamento, a maioria dos provadores certamente comprariam os frutos produzidos nos dois tipos de substrato. Seis provadores ficaram em dúvida se comprariam ou não comprariam o melão do substrato de fibra de coco, enquanto o do substrato de areia apenas um provador ficou em dúvida. 
Os provadores mudaram sua decisão de compra aos 21 dias de armazenamento, quando maior número certamente compraria o melão produzido com substrato de fibra de coco. Porém, aos 28 dias de armazenamento, 11 provadores certamente comprariam e 14 provavelmente comprariam o melão produzido no substrato de areia, ou seja, $83 \%$ dos provadores; no entanto, para o substrato fibra de coco, $56 \%$ tiveram essa decisão de compra.

Aos 42 dias de armazenamento, 50\% dos provadores certamente comprariam o melão submetido ao tratamento com areia (15 provadores) e $20 \%$ dos provadores certamente comprariam os frutos produzidos no substrato de fibra de coco (6 provadores), constatando-se que os mesmos ainda apresentavam características que permitiam sua comercialização. De acordo com os aspectos de aparência geral, cor, textura e sabor para esse período, o tratamento com areia foi o que apresentou maior valor médio, estando esses resultados diretamente relacionados com a aceitabilidade do consumidor. No tratamento com substrato de fibra de coco, aos 42 dias de armazenamento, apenas 20\% (6 provadores) certamente comprariam e 16\% (5 provadores) certamente não comprariam. Provavelmente, o que influenciou nessa decisão foi o sabor e a textura do produto que estavam comprometidos.

\section{CONCLUSÕES}

Aos 42 dias de armazenamento, tanto os melões produzidos no substrato com fibra de coco como na areia apresentaram-se aceitáveis pelo consumidor. No entanto, os produzidos no substrato com areia apresentaram melhor aceitabilidade e decisão de compra durante o armazenamento.

\section{AGRADECIMENTOS}

Ao Engenheiro Agrônomo Eduardo Xavier Nunes, Sócio-Diretor do viveiro HortMudas e aos seus funcionários.

\section{REFERÊNCIAS}

ALMEIDA, A.S. Conservação de melão Cantaloupe "Hy-Mark" tratado com 1-MCP após a colheita. 2002., 143 f. Dissertação (Mestrado em Fitotecnia) - Escola Superior de Agricultura de Mossoró, Mossoró 2002.

ALVES, R.E. Melão, pós-colheita. Brasília: Embrapa, 2000. 43 p. Comunicação para

Transferência de Tecnologia,

AWAD, M. Fisiologia de pós-colheita de frutos. São Paulo: Nobel, 1993. 151 p.

CARMO, S.A. Conservação pós-colheita de pimentão amarelo 'Zarco HS'. 2004. 108 f.

Dissertação (Mestrado em Engenharia Agrícola) - Faculdade de Engenharia Agrícola, Universidade Estadual de Campinas, Campinas, 2004.

CASTELLANE, P.D.; ARAUJO, J.A.C. Cultivo sem solo - hidroponia. Jaboticabal: FUNEP, 1995. $43 \mathrm{p}$.

CASTILLO, P.C.A. Avaliação de melão minimamente processado armazenado em diferentes temperaturas e embalagens. 2003. 78 f. Dissertação (Mestrado em Engenharia Agrícola) Faculdade de Engenharia Agrícola, Universidade Estadual de Campinas, Campinas, 2003.

CHITARRA, M.I.F. Processamento mínimo de frutos e hortaliças. Viçosa: Centro de Produções Técnicas, $1998.88 \mathrm{p}$.

COCOZZA, F.M. Aplicação pré-colheita de quelato de cálcio e boro em melão Gália: desenvolvimento e qualidade dos frutos. 1997. 78 f. Dissertação (Mestrado em Engenharia Agronômica) - Faculdade de Agronomia, Universidade Federal de Lavras, Lavras, 1997.

CORTEZ, L.A.B.; HONÓRIO, S.L.; MORETTI, C.L. Resfriamento de frutas e hortaliças. Brasília: Embrapa Informação Tecnológica, 2002., cap. 3, p.22-8. 
CUNHA, G.A.P. Manga para exportação: aspectos técnicos da produção. Ministério da Agricultura, do Abastecimento e da Reforma Agrária, Secretaria de Desenvolvimento Rural, Programa de Apoio à Produção e Exportação de Frutas, Hortaliças, Flores e Plantas Ornamentais. Brasília, 1994. 35 p. (Série Publicações Técnicas FRUPEX, 8).

FARIA, C.M.B.; COSTA, N.L.D.; SOARES, J.M.; PINTO, J.M.; LINS, J.M.; BRITO, L.T.L. Produção e qualidade de melão influenciados por matéria orgânica, nitrogênio e micronutrientes. Horticultura Brasileira, Brasília, v.21, n.1, p.55-9, 2003.

FONSECA, S.C.; OLIVEIRA, F.A.R.; BRECHT, J.K. Modelling respiration rate of fresh fruits and vegetables for modified atmosphere packages: a review. Journal of Food Engineering, Kidlington, v.52, n.1, p.99-119, 2002.

GUERRERO, L. La textura de los alimentos. Medidas sensoriales e instrumentales. Alimentación, Equipos y Tecnología, Madrid, v.12, n.10, p.45-8, 1993.

JACOMINO, A.P.; ARRUDA, M.C.; MOREIRA, M.C.; KLUGE, M.G. Processamento mínimo de frutas no Brasil. In: SIMPOSIUM "ESTADO ACTUAL DEL MERCADO DE FRUTAS Y VEGETALES EN IBEROAMÉRICANA”, 2004, San José, Costa Rica. Anales... p.79-86.

LIMA, M.A.C.; ALVES, R.E.; BISCEGLI, C.I.; FILGUEIRAS, H.A.C.; COCOZZA, F.M. Conservação pós-colheita de melões Galia 'Solar King' tratados com 1-metilciclopropeno. Horticultura Brasileira, Brasília, v.22, n.1, p.121-6, jan./mar. 2004.

MAGUIRE, K.M.; BANKS, N.H.; OPARA, L.U. Factors affecting weight loss of apples. Horticulture, Boston, v.25, p.197-234, 2001.

MENDONÇA, F.V.S.; MENEZES, J.B.; GUIMARÃES, A.A.; SOUZA, P.A.; SIMÕES, A.N.; SOUZA, G.L.F.M. Armazenamento do melão amarelo, híbrido RX20094, sob temperatura ambiente. Horticultura Brasileira, Brasília, v.22, n.1, p.76-79, jan./mar. 2004.

MENDONÇA, F.V.S.; MENEZES, J.B.; GOIS, V.A.; NUNES, G.H.S.; SOUZA, P.A.S.; MENDONÇA JÚNIOR, C.F. Armazenamento refrigerado de melão Orange Flesh. Horticultura Brasileira, Brasília, v.23, n.1, p.15-18, jan./mar. 2005.

MICCOLIS, V.; SALTVEIT, M.E. Influence of storage period and temperature on the postharvest characteristics of six melon (Cucumis melo L., Inodorus Group) cultivars. Postharvest Biology and Technology, Amsterdam, v.5, n.3, p.211-19, 1995.

MIR, N.; BEAUDRY, R. Atmosphere control using oxygen and carbon dioxide. In: KNEE, M. Fruit quality and its biological basis. Columbus: Sheffield Academic, 2002 p.122-149.

MORAIS, P.L.D.; MENEZES, J.B.; OLIVEIRA, O.F. Potencial de vida útil pós-colheita de quatro genótipos de melão tipo gália. Ciência Agrotécnica, Lavras, v.28, n.6, p.1314-20, nov./dez. 2004.

OLIVEIRA, S. B. Armazenamento refrigerado do melão (Cucumis melo) tipo Galia. 1992. 35 f. Monografia (Graduação em Agronomia) - Escola Superior de Agricultura de Mossoró, Mossoró, 1992.

PERONI, K.M.C. Influência do cloreto de cálcio sobre a vida de prateleira de melão 'amarelo' minimamente processado. 2002. 86 f. Dissertação (Mestrado em Ciências dos Alimentos) Universidade Federal de Lavras, Lavras, 2002.

VALERO, C; RUIZ, A.M. Equipos de medida de calidad organoléptica em frutas Fruticultura Professional, Barcelona, n.95, p.38-45, 1998.

VANETTI, M.C.D. Segurança microbiológica em produtos minimamente processados. In: ENCONTRO NACIONAL SOBRE PROCESSAMENTO MÍNIMO DE FRUTAS E HORTALIÇAS, 3., 2004, Viçosa. Palestras... Viçosa: UFV, 2004. p.30-2.

VICENTINI, N.M.; CASTRO, T.M.R.; CEREDA, M.P. Influência da fécula de mandioca na qualidade pós-colheita de frutos de pimentão (Capsicum annum L.). Ciência e Tecnologia de Alimentos, São Paulo, v.19, n.1, p.127-30, 1999. 